\title{
Effects of tranexamic acid on human nasal ciliary beat frequency
}

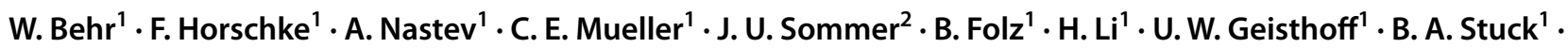 \\ R. Birk ${ }^{1}$
}

Received: 20 November 2020 / Accepted: 31 December 2020 / Published online: 4 February 2021

(c) The Author(s) 2021

\begin{abstract}
Background Patients with recurrent epistaxis, particularly due to hereditary hemorrhagic telangiectasia (HHT) are recommended to apply topical tranexamic acid (TXA) to reduce bleeding events. Those patients may suffer ciliary dysfunction due to TXA's effects on ciliary beating frequency (CBF) and their consequences.

Methodology/principal Human nasal epithelial cells were harvested with a nasal brush in 30 healthy subjects. We investigated the CBF in RPMI medium using high-frequency video microscopy. TXA was added to the cells in various concentrations ranging from 2 to $5 \%$, including the therapeutic concentration (2\%) and a control $(0 \%)$.

Results $\mathrm{CBF}$ in the control condition was $6.1 \pm 1.6 \mathrm{~Hz}$. TXA reduces $\mathrm{CBF}$ in a time and concentration dependent manner, to, e.g. $4.3 \pm 1.2 \mathrm{~Hz}$ with $2 \%$ TXA and $3.3 \pm 0.9 \mathrm{~Hz}$ with $5 \%$ TXA after 16-20 min. The differences in CBF were statistically significant for all concentrations of TXA.

Conclusions TXA has the potential to significantly impair nasal epithelial function. Therefore, frequent or regular topical nasal application of TXA should be done under close monitoring of nasal function, especially in patients with co-morbidities like chronic rhinosinusitis.
\end{abstract}

Keywords Tranexamic acid $\cdot$ Epistaxis $\cdot$ Ciliary beat frequency $\cdot$ CBF $\cdot$ Ciliary dysfunction

\section{Introduction}

The lifetime prevalence of epistaxis is $60 \%$, and between 6 and $10 \%$ of affected patients need medical help. It is, therefore, an important condition that can cause a reduced quality of life [1]. The most common cause of epistaxis is trauma and mechanical irritation [1]. Epistaxis occurs more frequently in patients who are elderly, have co-morbidities like hypertension, are on antiplatelet therapy or have hereditary hemorrhagic telangiectasia (HHT). There are a few first aid measures recommended to patients to reduce the need of medical interventions and to support self-help, like applying pressure to the nose or nasal self-packing [2].

W. Behr

wieland.behr@med.uni-marburg.de

1 Department of Otorhinolaryngology, Head and Neck Surgery, University Hospital Marburg, Philipps-Universität Marburg, Baldinger Straße 1, 35043 Marburg, Germany

2 Department of Otorhinolaryngology Head and Neck Surgery, University Hospital Wuppertal, Wuppertal, Germany
Local and systemic treatment with tranexamic acid (TXA) can also be used in the management of acute epistaxis. However, studies have shown inconclusive results in patients, regardless of whether they had HHT [3, 4]. Further preventative measures against recurrent epistaxis include application of nasal ointment or oil, nasal douching and avoidance of nose-blowing [5].

Even though there is no strong evidence of TXA's effectiveness in comparison to other topical medications [6], patients with recurrent epistaxis are still recommended to apply local TXA to prevent serious bleedings [7] due to its pharmacological mode of action. TXA has a lysine-like structure and blocks the formation of plasmin. It reduces the proteolytic activity of plasminogen activators, inhibits fibrinolysis and is also used in other specialties in the management of bleeds [8]. Previous studies have shown that TXA minimizes acute bleeding complications when it was given orally or intravenously. Contraindications of systemic treatment include a history of thrombosis, breastfeeding, intracranial hemorrhage, renal dysfunction, history of seizures, hyperfibrinolytic conditions or allergy. Adverse effects like diarrhea, nausea and vomiting, seizures, headache, 
allergic dermatitis and vision problems also need to be considered [8]. Side- and adverse effects for topical application of TXA are either not known or considered as negligible [9]. However, there are contraindications for topical TXA usage in neurosurgery as it could trigger severe convulsive seizures when applied directly contact to the central nervous system [10]. TXA is widely available and accessible, is easy to apply and, therefore, represents a viable alternative treatment to reduce bleeding events, hospital admissions and to improve overall quality of life [2]. In a study with patients with HHT, a nasal ciliary dysfunction was observed, suggested to be an after-effect of the treatment [11]. Nasal ciliary epithelium and nasal beat frequency (CBF) are important in the mucociliary clearance and cleaning and defense mechanism of the nose. Factors that influence CBF vary and include temperature [12], $\mathrm{pH}$ [13] and tobacco [14]. Other topical medications like alpha-sympathomimetic drugs [15], estrogen [11], polyhexanide [16], and oils [17] are also shown to influence CBF. Up to now, there are no studies analyzing the effect of TXA on CBF of nasal human epithelial cells.

\section{Materials and methods}

This study was carried out at the Department of Otorhinolaryngology, Head and Neck Surgery, University Hospital Marburg. The local ethics committee approved the study protocol (ref. number 117/19). Written informed consent was obtained from all participating subjects ( 15 female and 15 male). Exclusion criteria consisted of subjects under the age of 18 , smokers, and subjects with chronic or acute upper airway disease and previous surgery of the nose. The measurement protocol was standardized according to the methodology of previous studies $[16,18]$. Using a cytology brush, ciliary samples of the nose were harvested (Gynobrush Plus, Heinz Herenz, Hamburg, Germany). Standard procedure was to dip the brush in a $0.9 \%$ saline solution, before harvesting the cells via anterior rhinoscopy. Directly afterwards, a swap of each side of the nose was taken. Cell clusters were extracted out of middle and inferior nasal meatus by performing three full $360^{\circ}$ rotations while pushing the brush from the anterior part of the middle meatus to the back of the inferior turbinate. The brush was removed out of the nose carefully and the cells were dipped into $5 \mathrm{ml}$ of RPMI medium (RPMI 1640, cell culture tested, standard, L-glutamine: $300 \mathrm{mg} / \mathrm{l}$, PromoCell, Heidelberg, Germany) with a slow rotary motion to dislodge the cells into the medium. Previous studies have shown that CBF of the ciliated epithelial cells remains stable between 3 and $9 \mathrm{~h}$ after harvesting [19] and external influences like temperature might impact CBF $[20,21]$. Therefore, the medium was stored at $22{ }^{\circ} \mathrm{C}$ room temperature for $3 \mathrm{~h}$.
With a pipette $1000 \mu \mathrm{l}$ suspension of cells in RPMI were added in tissue culture plate (Sarstedt TC-Platte 6 Well Cell +, F. Sarstedt AG \& Co. KG, Nümbrecht, Germany). The plates were scanned for vital cell clusters with a magnification up to 630-fold. CBF was examined for 20 min using an inverted phase contrast microscope (Leica DM IL LED Fluo, Leica Microsystems GmbH, Wetzlar, Germany) and a high-speed video camera (BASLER acA 1300-200um), recording at 200 frames per second (fps). Video sequences with a duration of $2 \mathrm{sec}$ were recorded in 2-min intervals. Using the Sissons-Ammons-Video-Analysis (SAVA) software (Ammons Engineering, 8114 Flintlock Road, Mt. Morris, MI 48458, USA) the ciliary frequency of beating cells was measured three times in every sequence and the mean average CBF of the measurements was determined [22]. To analyse the CBF, the region of interest (ROI) method was selected by a blinded observer. Three ROIs were selected in each video sequence and the mean average $\mathrm{CBF}$ was calculated by the software. Observations for the medium without additional solutions were stopped after $20 \mathrm{~min}$, as no changes were seen within this time span. This group served as the negative control group.

To evaluate the effects of TXA, $500 \mu \mathrm{l}$ of the harvested RPMI cell solution and $500 \mu \mathrm{l}$ of $10 \%$ TXA-solution (Tranexamsäure $100 \mathrm{mg} / \mathrm{ml}$, CARINOPHARM GmbH, Elze, Germany) were mixed, to form a TXA concentration of 5\%. The same procedure was followed as described above for a time span of $30 \mathrm{~min}$ to determine the mean average CBF.

$200 \mu \mathrm{l}$ of $10 \%$ TXA-solution was added to $800 \mu \mathrm{l}$ of the cell-suspension to examine behavior of cilia in a $2 \%$ dilution. The same procedure to determine ROI was repeated for the $2 \%$ solutions. The TXA used in this study contained TXA, water and hydrochloric acid to adjust $\mathrm{pH}$ value. According to the technical information, the $\mathrm{pH}$ value of the TXA solution used lies between 6.5 and 7.5. To mitigate dilutional effects on ciliary beat frequency, water was tested in a separate measurement as a control. No significant changes in CBF were seen in the dilution of the RPMI-cell mixture and water 1:1 for $20 \mathrm{~min}$. Statistical analysis was completed via Mann-Whitney $U$ test using the open source program "R" [23].

\section{Results}

All recorded video sequences were analyzed successfully. Calculations showed a reduction of $\mathrm{CBF}$ with increasing concentrations of TXA. The mean average CBF measured over the entire period was $6.2 \pm 1.6 \mathrm{~Hz}$ in the control group (Table 1). In $2 \%$ TXA solution, the mean average CBF was $4.4 \pm 1.3 \mathrm{~Hz}$. In $5 \%$ TXA solution, there was a mean average CBF of $3.4 \pm 0.9 \mathrm{~Hz}$ (Table 1 ). 
Table 1 Ciliary beat frequency (CBF) in RPMI 1640, cell culture tested, standard, L-glutamine: $300 \mathrm{mg} / \mathrm{L}$, PromoCell, Heidelberg, Germany) and $2 \%$ and $5 \%$ suspension of tranexamic acid (TXA)

\begin{tabular}{|c|c|c|c|c|c|}
\hline \multicolumn{2}{|c|}{ Negative control } & \multicolumn{2}{|l|}{ TXA $2 \%$} & \multicolumn{2}{|l|}{ TXA 5\% } \\
\hline Time (min) & $\mathrm{CBF}$ & Time (min) & $\mathrm{CBF}$ & Time (min) & $\mathrm{CBF}$ \\
\hline 2 & $6.7 \pm 1.4 \mathrm{~Hz}$ & 2 & $5.3 \pm 1.6 \mathrm{~Hz}$ & 2 & $3.9 \pm 1.0 \mathrm{~Hz}$ \\
\hline 6 & $6.2 \pm 1.6 \mathrm{~Hz}$ & 6 & $4.7 \pm 1.2 \mathrm{~Hz}$ & 6 & $3.6 \pm 0.9 \mathrm{~Hz}$ \\
\hline 12 & $6.2 \pm 1.6 \mathrm{~Hz}$ & 12 & $4.2 \pm 1.1 \mathrm{~Hz}$ & 12 & $3.4 \pm 1.0 \mathrm{~Hz}$ \\
\hline $16-20$ & $6.1 \pm 1.6 \mathrm{~Hz}$ & $16-20$ & $4.3 \pm 1.2 \mathrm{~Hz}$ & $16-20$ & $3.3 \pm 0.9 \mathrm{~Hz}$ \\
\hline
\end{tabular}

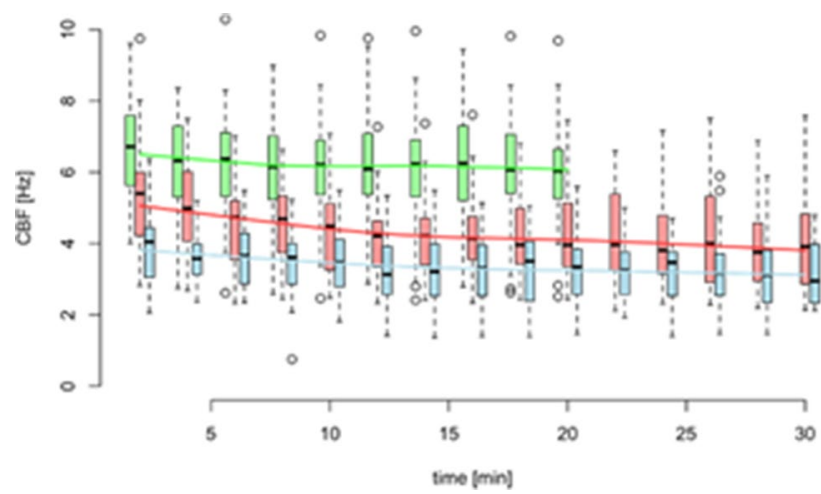

Fig. 1 Boxplot of ciliary beat frequency (CBF) in concentrate with $0 \%$ (green), 2\% (red) and 5\% (blue) concentrate of TXA. The boxes show interquartile range (IQR) with whiskers extending up to 1.5 times the IQR. The solid line marks the median. $\mathrm{CBF}$ in $\mathrm{Hz}$, time in $\min . N=30$

The difference of the average mean CBF in both TXA concentration groups of $2 \%$ and $5 \%$ were statistically significant compared to the control group at each point of time. For example, the $p$ value for the difference of the mean CBF of the control group versus TXA $2 \%$ at $t=2$ min was $<0.0001$. These highly significant results extend over the entire measurement period for both concentrations. Graphical interpretation is shown in Figs. 1 and 2 in a box-and-whisker plot and a three-dimensional diagram.

\section{Discussion}

Studies have shown a reduced CBF in patients with chronic rhinosinusitis or rhinitis [24, 25], as well as chronic obstructive pulmonary disease (COPD) [26]. Recent studies suggest that patients with HHT may also have a reduced CBF [11]. The results in this study show that TXA reduces CBF significantly in vitro and consequently, may reduce mucociliary clearance in vivo. This is clinically relevant, as impaired mucociliary clearance can impair respiratory defense mechanisms and consequently lead to biofilm formations and relapsing and chronic infections [27].

Bleeding events are the most common presenting complaint in patients with HHT. Patients suffering from recurrent

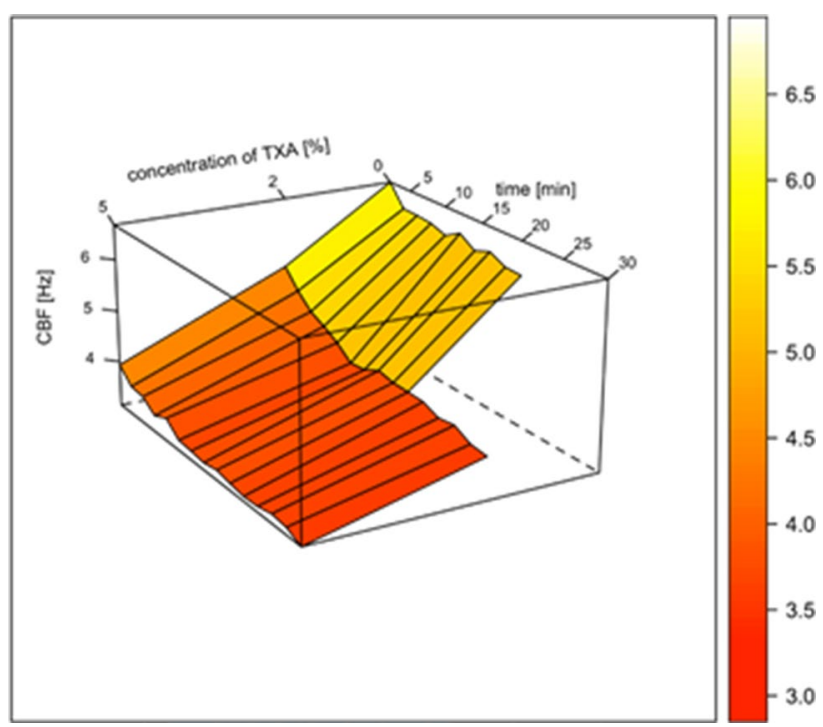

Fig. 2 3D diagram of time- and concentration-dependent changes of ciliary beat frequency $(\mathrm{CBF})$ by TXA in vitro. $\mathrm{CBF}$ in $\mathrm{Hz}$, time in $\min . N=30$

epistaxis need a multimodal management plan, including self-administered treatments [28], as discussed above.

To draw conclusions regarding everyday clinical practice, a distinction should be made between acute treatment and long-term therapy with TXA. The use of topical TXA is a common treatment option in the management of acute epistaxis and is supported by some studies with positive results $[29,30]$. It is less invasive and better tolerated than nasal packing or coagulation, which is often painful for patients [31]. The length of hospital stay in patients who were managed with topical TXA compared to patients who received standard care of epistaxis was also not found to be significantly statistically different [3].

Quality of life increases with less hospitalizations [2]. A systematic review has shown that topical TXA reduces bleeding events and the need for blood transfusions in general surgery [4]. Self-management options in epistaxis, like topical application of TXA or nasal self-packing, can also increase the perceived quality of life [6]. However, there are yet no studies on self-administered topical TXA ointment and their effects on preventing epistaxis episodes. The only 
existing study has relevant limitations, as the application form was not standardized [6].

Our data indicate that frequent nasal application of TXA should be provided with caution as prophylaxis for epistaxis, especially when the patient has other comorbidities like chronic rhinosinusitis. Patients with HHT usually undergo multiple surgical interventions in the nose. As a result, the anatomy and physiology are often altered with scars and damaged mucosal membranes. Furthermore, it is suggested that patients with HHT may have reduced CBF [11] and may have other nasal anomalies like respiratory epithelial adenomatoid hamartoma (REAH) [32].

A possible cause for the reduced CBF may be the change in $\mathrm{pH}$ value of the ciliated cells. Previous studies have shown that acidic $\mathrm{pH}$ values under 7 significantly reduces the $\mathrm{CBF}$ of bronchiolar ciliated cells [33]. Another group demonstrated that nasal saline irrigations with different $\mathrm{pH}$ values have varying effects on nasal symptoms and presumably has an impact on mucociliary clearance [13]. The $\mathrm{pH}$ value of the TXA in this study was between 6.5 and 7.5. Physiological $\mathrm{pH}$ in the nose is 6.8 [34].

The risk of additional mucociliary dysfunction must be considered and patients should be informed. Based on our data, we recommend that patients with a pre-existing chronic inflammation of the upper airways should be closely monitored by an ENT specialist. If there have been no bleeding events for several months, the use of topical TXA may be considered to be reduced or stopped. The risks and benefits should be weighed carefully, especially in patients with HHT. If recurrent epistaxis cannot be controlled conservatively, surgical interventions like nasal occlusion should be considered in an experienced center [35]. Long-term use of TXA in HHT patients could possibly further damage already strained nasal mucosa and consequently lead to biofilm formation with bacterial colonization, chronic inflammation and nasal congestion. This would significantly affect the normal physiological tasks of the nose, such as warming and humidification of air [36].

\section{Limitations of the study}

The present study is an in vitro study without examination of the long-term use of TXA and, therefore, only allows to draw limited conclusions for the clinical practice. In addition, conclusions regarding mucociliary clearance in vivo, especially in patients with in HHT with potentially damaged mucosa, can only be drawn to a limited extent. Another limitation includes the delay of 1-2 min between the application of TXA and the first measurement of CBF as this time was required for the identification of a beating cell cluster. Consequently, we are unable to determine the speed of TXA's effects on CBF until the first video sequence. However, the effects of the delay were minimized by taking measurements for at least $20 \mathrm{~min}$. The in vivo $\mathrm{CBF}$ and the impact of external influences may also be underestimated in this study. Possible effects of other ingredients of established TXA mixture (e.g. ointment: $1,5 \mathrm{~g}$ tranexamic acid, $25 \mathrm{~g}$ paraffinum (sub) liquidum, $25 \mathrm{~g}$ lanolin, $35 \mathrm{~g}$ Unguentum Cordes ${ }^{\circledR}$ ) and the reversibility of CBF have not been assessed.

\section{Conclusion}

The aim of this study was to evaluate the impact of TXA on CBF. The results show that TXA reduces CBF significantly. Therefore, long-term use of TXA to prevent epistaxis should be considered with care.

Author contributions The design of the study was planned by RB, WB and FH. FH and WB carried out the experiments. WB and RB wrote the article. RB and US performed statistical analysis. AN, EM, US, BF, HL, UWG and BAS gave advice in interpretation of results and contributed critical feedback and thereby improved the article. All authors carefully read and commented on the article.

Funding Open Access funding enabled and organized by Projekt DEAL. The funding was provided by Department of Otorhinolaryngology, University Hospital Marburg, Philipps-Universität Marburg, Germany.

Availability of data and material Information about data and material is given in the paper and references.

Code availability Not applicable.

\section{Compliance with ethical standards}

Conflict of interest The authors have no conflict of interest.

Ethical approval Local ethics committee approved the study protocol (ref. number 117/19).

Consent of participate All participants signed informed consent.

Consent for publication All author and co-authors agreed for the publication.

Open Access This article is licensed under a Creative Commons Attribution 4.0 International License, which permits use, sharing, adaptation, distribution and reproduction in any medium or format, as long as you give appropriate credit to the original author(s) and the source, provide a link to the Creative Commons licence, and indicate if changes were made. The images or other third party material in this article are included in the article's Creative Commons licence, unless indicated otherwise in a credit line to the material. If material is not included in the article's Creative Commons licence and your intended use is not permitted by statutory regulation or exceeds the permitted use, you will need to obtain permission directly from the copyright holder. To view a copy of this licence, visit http://creativecommons.org/licenses/by/4.0/. 


\section{References}

1. Beck R, Sorge M, Schneider A, Dietz A (2018) Current approaches to epistaxis treatment in primary and secondary care. Dtsch Arztebl Int 115(1-02):12-22. https://doi.org/10.3238/arzte bl.2018.0012

2. Droege F, Lueb C, Thangavelu K, Stuck BA, Lang S, Geisthoff U (2019) Nasal self-packing for epistaxis in Hereditary Hemorrhagic Telangiectasia increases quality of life. Rhinology 57(3):231-239. https://doi.org/10.4193/Rhin18.141

3. Birmingham AR, Mah ND, Ran R, Hansen M (2018) Topical tranexamic acid for the treatment of acute epistaxis in the emergency department. Am J Emerg Med 36(7):1242-1245. https:// doi.org/10.1016/j.ajem.2018.03.039

4. Ker K, Beecher D, Roberts I (2013) Topical application of tranexamic acid for the reduction of bleeding. Cochrane Database Syst Rev 7:CD010562. https://doi.org/10.1002/14651858.CD010 562.pub2

5. Diamond L (2014) Managing epistaxis. JAAPA 27(11):35-39. https://doi.org/10.1097/01.JAA.0000455643.58683.26

6. Whitehead KJ, Sautter NB, McWilliams JP, Chakinala MM, Merlo CA, Johnson MH, James M, Everett EM, Clancy MS, Faughnan ME, Oh SP, Olitsky SE, Pyeritz RE, Gossage JR (2016) Effect of topical intranasal therapy on epistaxis frequency in patients with hereditary hemorrhagic telangiectasia: a randomized clinical trial. JAMA 316(9):943-951. https://doi.org/10.1001/jama.2016.11724

7. Klepfish A, Berrebi A, Schattner A (2001) Intranasal tranexamic acid treatment for severe epistaxis in hereditary hemorrhagic telangiectasia. Arch Intern Med 161(5):767. https://doi.org/10.1001/ archinte.161.5.767

8. Chauncey JM, Wieters JS (2020) Tranexamic acid. In: StatPearls. Treasure Island (FL): StatPearls Publishing

9. Pundir V, Pundir J, Georgalas C, Fokkens WJ (2013) Role of tranexamic acid in endoscopic sinus surgery-a systematic review and meta-analysis. Rhinology 51(4):291-297. https://doi. org/10.4193/Rhin13.042

10. Schlag MG, Hopf R, Redl H (2000) Convulsive seizures following subdural application of fibrin sealant containing tranexamic acid in a rat model. Neurosurgery 47(6):1463-1467

11. Sommer JU, Stuck BA, Heiser C, Kassner SS, Hormann K, Sadick $\mathrm{H}$ (2011) Ciliary function of the nose in patients with Osler's disease and the effect of topically applied estrogens as a nose ointment. Rhinology 49(4):407-412. https://doi.org/10.4193/Rhino 11.046

12. Green A, Smallman LA, Logan AC, Drake-Lee AB (1995) The effect of temperature on nasal ciliary beat frequency. Clin Otolaryngol Allied Sci 20(2):178-180. https://doi. org/10.1111/j.1365-2273.1995.tb00040.x

13. Chusakul S, Warathanasin S, Suksangpanya N, Phannaso C, Ruxrungtham S, Snidvongs K, Aeumjaturapat S (2013) Comparison of buffered and nonbuffered nasal saline irrigations in treating allergic rhinitis. Laryngoscope 123(1):53-56. https://doi. org/10.1002/lary.23617

14. Zhou H, Wang X, Brighton L, Hazucha M, Jaspers I, Carson JL (2009) Increased nasal epithelial ciliary beat frequency associated with lifestyle tobacco smoke exposure. Inhal Toxicol 21(10):875881. https://doi.org/10.1080/08958370802555898

15. Mickenhagen A, Siefer O, Neugebauer P, Stennert E (2008) The influence of different alpha-sympathomimetic drugs and benzalkoniumchloride on the ciliary beat frequency of in vitro cultured human nasal mucosa cells. Laryngorhinootol 87(1):30-38. https ://doi.org/10.1055/s-2007-966891

16. Birk R, Aderhold C, Stern-Strater J, Hormann K, Stuck BA, Sommer JU (2015) Polyhexanide-containing solution reduces ciliary beat frequency of human nasal epithelial cells in vitro. Eur Arch
Otorhinolaryngol 272(2):377-383. https://doi.org/10.1007/s0040 5-014-3112-5

17. Neher A, Gstottner M, Thaurer M, Augustijns P, Reinelt M, Schobersberger W (2008) Influence of essential and fatty oils on ciliary beat frequency of human nasal epithelial cells. Am J Rhinol 22(2):130-134. https://doi.org/10.2500/ajr.2008.22.3137

18. Birk R, Aderhold C, Wenzel A, Eschenhagen T, Kramer B, Hormann K, Stuck BA, Sommer JU (2016) Mupirocin reduces ciliary beat frequency of human nasal epithelial cells. Eur Arch Otorhinolaryngol 273(12):4335-4341. https://doi.org/10.1007/s0040 5-016-4161-8

19. Sommer JU, Gross S, Hormann K, Stuck BA (2010) Timedependent changes in nasal ciliary beat frequency. Eur Arch Otorhinolaryngol 267(9):1383-1387. https://doi.org/10.1007/ s00405-010-1211-5

20. Jorissen M, Bessems A (1995) Influence of culture duration and ciliogenesis on the relationship between ciliary beat frequency and temperature in nasal epithelial cells. Eur Arch Otorhinolaryngol 252(8):451-454. https://doi.org/10.1007/BF02114748

21. Sauvalle M, Alvo A (2018) Effect of the temperature of nasal lavages on mucociliary clearance: a randomised controlled trial. Eur Arch Otorhinolaryngol 275(9):2403-2406. https://doi. org/10.1007/s00405-018-5060-y

22. Sisson JH, Stoner JA, Ammons BA, Wyatt TA (2003) All-digital image capture and whole-field analysis of ciliary beat frequency. J Microsc 211(Pt 2):103-111. https://doi.org/10.104 6/j.1365-2818.2003.01209.x

23. R Development Core Team (2020) R: a language and environment for statistical computing. R Foundation for statistical Computing, Vienna, Austria

24. Tint D, Kubala S, Toskala E (2016) Risk factors and comorbidities in chronic rhinosinusitis. Curr Allergy Asthma Rep 16(2):16. https ://doi.org/10.1007/s11882-015-0589-y

25. Chen B, Shaari J, Claire SE, Palmer JN, Chiu AG, Kennedy DW, Cohen NA (2006) Altered sinonasal ciliary dynamics in chronic rhinosinusitis. Am J Rhinol 20(3):325-329. https://doi. org/10.2500/ajr.2006.20.2870

26. Yaghi A, Zaman A, Cox G, Dolovich MB (2012) Ciliary beating is depressed in nasal cilia from chronic obstructive pulmonary disease subjects. Respir Med 106(8):1139-1147. https://doi. org/10.1016/j.rmed.2012.04.001

27. Gelardi M, Passalacqua G, Fiorella ML, Quaranta N (2013) Assessment of biofilm by nasal cytology in different forms of rhinitis and its functional correlations. Eur Ann Allergy Clin Immunol 45(1):25-29

28. Droege F, Thangavelu K, Stuck BA, Stang A, Lang S, Geisthoff U (2018) Life expectancy and comorbidities in patients with hereditary hemorrhagic telangiectasia. Vasc Med 23(4):377-383. https ://doi.org/10.1177/1358863X18767761

29. Whitworth K, Johnson J, Wisniewski S, Schrader M (2019) Comparative effectiveness of topically administered tranexamic acid versus topical oxymetazoline spray for achieving hemostasis in epistaxis. J Emerg Med. https://doi.org/10.1016/j.jemer med.2019.11.038

30. Joseph J, Martinez-Devesa P, Bellorini J, Burton MJ (2018) Tranexamic acid for patients with nasal haemorrhage (epistaxis). Cochrane Database Syst Rev 12:CD004328. https://doi. org/10.1002/14651858.CD004328.pub3

31. Zahed R, Mousavi Jazayeri MH, Naderi A, Naderpour Z, Saeedi M (2018) Topical tranexamic acid compared with anterior nasal packing for treatment of epistaxis in patients taking antiplatelet drugs: randomized controlled trial. Acad Emerg Med 25(3):261266. https://doi.org/10.1111/acem. 13345

32. Hawley KA, Pabon S, Hoschar AP, Sindwani R (2013) The presentation and clinical significance of sinonasal respiratory 
epithelial adenomatoid hamartoma (REAH). Int Forum Allergy Rhinol 3(3):248-253. https://doi.org/10.1002/alr.21083

33. Clary-Meinesz C, Mouroux J, Cosson J, Huitorel P, Blaive B (1998) Influence of external $\mathrm{pH}$ on ciliary beat frequency in human bronchi and bronchioles. Eur Respir J 11(2):330-333. https ://doi.org/10.1183/09031936.98.11020330

34. Zippel R, Ebel R (1972) Comparative pH-measurements of the mucosa of nose and mouth in healthy and laryngectomized persons. Arch Klin Exp Ohren Nasen Kehlkopfheilkd 201(1):49-56

35. Thomson RS, Molin NL, Whitehead KJ, Ashby S, Johnson L, Ward PD, McRae BR, Wilson KF, McDonald J (2018) The effects of nasal closure on quality of life in patients with hereditary hemorrhagic telangiectasia. Laryngoscop Invest Otolaryngol 3(3):178-181. https://doi.org/10.1002/lio2.157

36. Vent $\mathbf{J}$ (2017) The nose and its function. Facial Plast Surg 33(4):365-366. https://doi.org/10.1055/s-0037-1604176

Publisher's Note Springer Nature remains neutral with regard to jurisdictional claims in published maps and institutional affiliations. 